\title{
7 CMS Reimbursement Reform and the Incidence of Hospital-Acquired Pulmonary Embolism or Deep Vein Thrombosis
}

\author{
Risha Gidwani, Dr.P.H. ${ }^{1,2,3,4}$ and Jay Bhattacharya, M.D., Ph.D. ${ }^{4}$
}

${ }^{1}$ VA Health Economics Resource Center, Menlo Park, CA, USA; ${ }^{2}$ VA Center for Innovation to Implementation, Menlo Park, CA, USA; ${ }^{3}$ Department of Medicine, Stanford University, Stanford, CA, USA; ${ }^{4}$ Centers for Health Policy, Primary Care and Outcomes Research, Stanford University, Stanford, CA, USA.

BACKGROUND: In October 2008, the Centers for Medicare \& Medicaid Services (CMS) stopped reimbursing hospitals for the marginal cost of treating certain preventable hospital-acquired conditions.

OBJECTIVE: This study evaluates whether CMS's refusal to pay for hospital-acquired pulmonary embolism (PE) or deep vein thrombosis (DVT) resulted in a lower incidence of these conditions.

DESIGN: We employ difference-in-differences modeling using 2007-2009 data from the Nationwide Inpatient Sample, an all-payer database of inpatient discharges in the U.S. Discharges between 1 January 2007 and 30 September 2008 were considered "before payment reform;" discharges between 1 October 2008 and 31 December 2009 were considered "after payment reform." Hierarchical regression models were fit to account for clustering of observations within hospitals.

PARTICIPANTS: The "before payment reform" and "after payment reform" incidences of PE or DVT among 65-69year-old Medicare recipients were compared with three different control groups of: a) 60-64-year-old nonMedicare patients; b) 65-69-year-old non-Medicare patients; and c) 65-69-year-old privately insured patients. Hospital reimbursements for the control groups were not affected by payment reform.

INTERVENTION: CMS payment reform for hospitalbased reimbursement of patients with hip and knee replacement surgeries.

MAIN MEASURES: The outcome was the incidence proportion of hip and knee replacement surgery admissions that developed pulmonary embolism or deep vein thrombosis.

KEY RESULTS: At baseline, pulmonary embolism or deep vein thrombosis were present in $0.81 \%$ of all hip or knee replacement surgeries for Medicare patients aged 65-69 years old. CMS payment reform resulted in a $35 \%$ lower incidence of hospital-acquired pulmonary embolism or deep vein thrombosis in these patients $(p=0.015)$. Results were robust to sensitivity analyses.

CONCLUSION: CMS's refusal to pay for hospital-acquired conditions resulted in a lower incidence of hospitalacquired pulmonary embolism or deep vein thrombosis after hip or knee replacement surgery. Payment reform had the desired direction of effect.

Received March 17, 2014

Revised September 19, 2014

Accepted October 16, 2014

Published online December 18, 2014
KEY WORDS: payment reform; pay-for-performance; hospital-acquired conditions; pulmonary embolism; deep vein thrombosis.

J Gen Intern Med 30(5):588-96

DOI: $10.1007 / \mathrm{s} 11606-014-3087-3$

(C) Society of General Internal Medicine 2014

\section{INTRODUCTION}

In 2008, the Centers for Medicare \& Medicaid Services (CMS) implemented hospital payment reform, no longer reimbursing hospitals for the treatment of certain conditions if patients acquired them after admission. The goal of this payment reform was to improve patient outcomes through the avoidance of hospital-acquired conditions.

CMS reimburses hospitals for inpatient admissions based on the Medicare Severity Diagnosis-Related Group, or MS-DRG system. The MS-DRG system has three payment levels, each corresponding to the intensity of care required to treat a patient. The base level represents care without any complication or comorbidity. Admissions with a complication or comorbidity (CC) are reimbursed at a higher rate, and admissions with a major complication or comorbidity (MCC) are reimbursed at the highest rate. MS-DRGs with an MCC can be reimbursed up to three times that of an MS-DRG with no CC or MCC. ${ }^{1}$ This increased payment for comorbidities (conditions that are present on patient admission to the hospital) results in higher reimbursements for sicker patients. However, increased payments for complications, or conditions that develop as a result of patients' experience in the hospital (i.e., hospital-acquired conditions), financially reward hospitals that may be providing poor care to their patients.

Recognizing this perverse incentive, on 1 October 2008, CMS stopped reimbursing hospitals for nine types of hospitalacquired conditions. These nine categories of conditions were: foreign object retained after surgery; air embolism; blood incompatibility in transfusion; Stage III and IV pressure ulcers; falls and trauma; manifestations of poor glycemic control; catheter-associated infection; surgical site infections after certain orthopedic procedures, coronary-artery bypass grafts or bariatric surgeries; and deep vein thrombosis and pulmonary embolism after hip or knee replacement. ${ }^{1}$ These 
conditions were chosen because they are: 1) high cost, high volume or both; 2) result in the assignment of a higherreimbursed MS-DRG; and 3) are considered to be reasonably preventable through the application of evidence-based guidelines. ${ }^{2}$ If the patient developed one of these conditions after admission, CMS's new payment program would reimburse a hospital for the cost of treating that patient exclusive of costs specific to the hospital-acquired condition. Prior to implementation, CMS estimated the total nationwide payment impact of the policy to be $\$ 20$ million in the first year and $\$ 50$ million in subsequent years. ${ }^{3}$

Here, we evaluate whether CMS's refusal to pay for hospital-acquired conditions was associated with a lower incidence of hospital-acquired pulmonary embolism (PE) or deep vein thrombosis (DVT) in patients undergoing hip or knee replacement surgery. Hip or knee replacements are commonly performed procedures in the United States; 1,062,063 such procedures were performed in the United States in 2011, with 600,392 surgeries being paid for by Medicare. ${ }^{4}$ Patients undergoing hip or knee arthroplasty are at high risk for PE or DVT; thromboembolism is the most frequently occurring complication following hip or knee replacement surgery. ${ }^{5}$ The Office of the Surgeon General considers PE and DVT to be major public health problems, and estimates more than 350,000 people are affected by PE or DVT each year. ${ }^{6}$ In the absence of prophylaxis, approximately $50 \%$ of hip replacement patients will develop DVT and as many as $20 \%$ will develop PE. In knee replacement patients who do not receive prophylaxis, more than three-quarters will develop DVT and approximately $7 \%$ will develop PE. ${ }^{5}$ These complications can be prevented with appropriate care. ${ }^{7,8}$

While tying hospital reimbursement to achievement of quality goals, also known as pay-for-performance, has become more widespread, evidence indicates that the effect of these programs on patient outcomes is mixed. ${ }^{9-14}$ However, unlike previous hospital-based pay-for-performance programs in which hospitals voluntarily participated, the CMS hospitalacquired conditions initiative affects all Medicare-reimbursed hospitals nationwide. Economic arguments regarding loss aversion also suggest that this program may be successful; penalty avoidance may be more of an impetus to action than capturing potential gains. ${ }^{15}$ We sought to evaluate the impact of this mandatory and punitive pay-for-performance initiative on patient outcomes.

\section{METHODS}

Data were obtained from the 2007 to 2009 Healthcare Cost and Utilization Project (HCUP) Nationwide Inpatient Sample (NIS). The NIS is the largest publicly available all-payer database of hospital discharges in the United States. It contains encounter-level administrative data, including ICD-9-CM diagnosis and procedure codes, from roughly 1,000 hospitals nationwide. The NIS approximates a $20 \%$ sample of U.S. community hospitals, defined as non-Federal, short-term, general, and other specialty hospitals, and uses sampling weights to ensure that data are nationally representative. Encounters for hip and knee replacement were identified by principal procedure ICD-9-CM codes 00.85, 00.86, 00.87, 81.51, 81.52, or 81.54; diagnoses of PE or DVT were identified using CMS's recommended methodology. ${ }^{16}$

Our analysis uses a difference-in-difference modeling approach, which is essentially a pre-post analysis with a control group. Difference-in-difference modeling is a quasiexperimental approach used when it is infeasible to conduct a randomized controlled trial. For this reason, difference-indifference modeling has been extensively used in the economics literature, ${ }^{17-20}$ and is beginning to be applied in health policy research..$^{21-23}$ In observational data, patients in a treatment and a control group are likely to have systematic differences that affect their likelihood of exposure (selection bias). Comparing pre-intervention and post-intervention data for a treatment group can mitigate selection bias, but one risks erroneously attributing changes to the intervention when in fact they are driven by larger environmental trends. In the standard difference-in-difference approach, outcomes are observed for two groups for two time periods. One of the groups is exposed to the intervention in the second time period but not in the first (treatment group). The other group is not exposed to the intervention in either time period (control group). Comparing pre-post data in the control group to pre-post data in the treatment group serves to remove biases that may be due to larger trends in the environment as well as biases that may be due to systematic differences across the treatment and control groups. The assumption underlying difference-in-difference modeling is that the difference in the change in outcome amongst treatment and control groups is the result of the intervention; in the absence of the intervention, the trend line would be parallel across the treatment and control groups.

In this analysis, the intervention is payment reform, the treatment group is Medicare patients receiving hip or knee surgery, and the control group is non-Medicare patients receiving hip and knee surgery. The first "difference" is the intervention period. All encounters with a discharge date between 1 January 2007 and 30 September 2008 were considered pre-intervention; encounters with a discharge date between 1 October 2008 and 31 December 2009 were considered post-intervention. Allocating data to two time periods of pre-implementation and post-implementation prevents problems with serial correlation. ${ }^{24}$ The second "difference" was the patient group: Medicare ("treatment") versus non-Medicare ("control"). We ran three models to test various specifications of the control group. In our first model, the control group was non-Medicare patients aged 60-64 years. One becomes eligible for Medicare at the age of 65 or through disability. There are therefore inherent age differences across Medicare and non-Medicare populations. In order to make groups as similar as possible with respect to age, the Medicare group was restricted to persons aged 65-69 years and the non-Medicare 
group to persons aged 60-64. We were also cognizant that CMS payment reform could create differential incentives to code for PE or DVT across Medicare and non-Medicare populations. To test whether coding incentives were influencing model results, we ran a second model in which the control group was patients aged 65-69 without Medicare as a primary payer. If hospital billing departments use payer-specific billing software, and coding was influenced by a financial incentive to not record PE or DVT in the Medicare population, one would expect to see a significant difference in PE or DVT amongst the non-Medicare and Medicare populations. Furthering this exploration of whether model results were influenced by hospital coding incentives, we also employed a third control group of patients aged 65-69 years with private insurance as the primary payer. More details about the difference-in-difference statistical approach can be found in the Appendix.

We employ a hierarchical regression model to examine the impact of CMS payment reform after adjusting for race, sex, hospital region, teaching hospital status, elective admission, rural hospital status, and median household income quartile for patient zip code. Covariates were selected based on investigator judgment, as well as examination of point estimates and $p$ values from univariate analyses. Adjusted analyses were performed as a hierarchical, or mixed-effects, linear probability regression, with hospital identifier serving as a random intercept to account for lack of independence of discharges within a hospital, and all other covariates identified as fixed effects. ${ }^{25}$ Finite population corrections were not used due to the desire to make inferences regarding the population of hospitals in the United States, rather than simply the sample of hospitals present in the NIS. ${ }^{26}$ Robust standard errors were employed to handle heteroskedasticity. ${ }^{27}$ Alternate model specifications were also tested to examine robustness of model results. All statistical analyses were performed using STATA software, version 12.0 (StataCorp).

With each additional year, the NIS adds data from more states. In 2007, the NIS contained data from 40 states; in 2009, the NIS contained data from 44 states. In order to ensure that state data remained constant across years of analysis, states for which all 3 years of data were not available (Louisiana, Pennsylvania, Montana and New Mexico) were dropped from the analysis. Data from Maine were dropped because primary payer data were not available.

\section{RESULTS}

There were 136,634 encounters for hip or knee replacement surgery from 2007 to 2009 in patients aged 60-69 years. These orthopedic procedures occurred with similar frequency across the treatment and control groups; from 2007 to 2009, there were 69,263 hip or knee replacement surgeries in Medicare patients aged 65-69 years, and 67,371 such surgeries in 60-64 year-olds not covered by Medicare (Table 1). There were more females, fewer teaching hospitals, and slightly
Table 1. PE or DVT in Hip or Knee Surgeries, Unadjusted, by Year

\begin{tabular}{|c|c|c|c|c|}
\hline Year & Group & $\begin{array}{l}\text { \# of PE } \\
\text { or DVT }\end{array}$ & $\begin{array}{l}\text { \# of Hip } \\
\text { or Knee } \\
\text { Replacement } \\
\text { Surgeries }\end{array}$ & $\%$ \\
\hline \multirow[t]{2}{*}{2007} & $\begin{array}{l}60-64 \text { year-olds } \\
\text { not in Medicare }\end{array}$ & 152 & 21,654 & $0.70 \%$ \\
\hline & $\begin{array}{l}\text { 65-69 year-olds } \\
\text { in Medicare }\end{array}$ & 185 & 22,779 & $0.81 \%$ \\
\hline \multirow[t]{2}{*}{2008} & $\begin{array}{l}\text { 60-64 year-olds } \\
\text { not in Medicare }\end{array}$ & 150 & 23,076 & $0.65 \%$ \\
\hline & $\begin{array}{l}\text { 65-69 year-olds } \\
\text { in Medicare }\end{array}$ & 193 & 23,371 & $0.83 \%$ \\
\hline \multirow[t]{2}{*}{2009} & $\begin{array}{l}\text { 60-64 year-olds } \\
\text { not in Medicare }\end{array}$ & 189 & 22,641 & $0.83 \%$ \\
\hline & $\begin{array}{l}65-69 \text { year-olds } \\
\text { in Medicare }\end{array}$ & 164 & 23,113 & $0.71 \%$ \\
\hline Total & Entire sample & 1,033 & 136,634 & $0.76 \%$ \\
\hline
\end{tabular}

more urban hospitals in the Medicare group (Table 2). There were also some differences amongst patients with respect to median household income quartile for patient zip code, and hospital region. P values are not reported here due to large sample sizes causing statistically significant results.

Regression models indicate CMS reimbursement was associated with a reduction in hospital-acquired PE or DVT in hip or knee surgeries amongst Medicare patients aged 65-69 years. We focus here on Model 1 results, as they best meet the parallel trends assumption required for difference-in-difference modeling. After adjusting for race, sex, hospital region, teaching hospital status, elective admission, rural hospital status, and median houseful income quartile for patient zip code, the CMS policy change was associated with a 0.28 percentage point reduction in the incidence proportion of hip or knee encounters with PE or DVT (Model 1, Table 3). At baseline, pulmonary embolism or deep vein thrombosis was present in $0.81 \%$ of all hip or knee replacement surgeries for Medicare patients aged 65-69 years old; CMS payment reform was therefore associated with a $35 \%$ lower incidence of hospital-acquired pulmonary embolism or deep vein thrombosis in these patients. This reduction was statistically significant $(p=0.015)$. The incidence of PE or DVT in these orthopedic encounters increased from the pre-intervention to the post-intervention period for non-Medicare patients aged 60-64 years, while it declined in that same period for Medicare patients aged 65-69 (Fig. 1).

Other significant independent predictors of hospitalacquired PE or DVT were teaching hospital status and length of stay (Table 3). The independent effect of teaching hospitals was large compared with many other variables included in the model; patients seen at teaching hospitals were 0.32 percentage points more likely to develop PE or DVT compared with patients seen at non-teaching hospitals $(p=0.001)$. Length of stay was the single largest predictor of developing a PE or DVT; patients with a 1-day increase in length of stay had a 0.50 percentage point higher chance of developing PE or DVT $(p<0.0001)$. Hospital region or rural location was not associated with incidence of PE or DVT. 
Table 2 Demographic Characteristics

\begin{tabular}{|c|c|c|c|c|}
\hline Category & Pre-intervention & Post-intervention & $\begin{array}{l}\text { 60-64 year-olds } \\
\text { not in Medicare }\end{array}$ & $\begin{array}{l}\text { 65-69 year-olds } \\
\text { in Medicare }\end{array}$ \\
\hline Age Mean (SD) & $64.5(2.9)$ & $64.5(2.9)$ & $61.9(1.4)$ & $67.0(1.4)$ \\
\hline Female & $60.7 \%$ & $62.0 \%$ & $59.1 \%$ & $63.7 \%$ \\
\hline \multicolumn{5}{|l|}{ Race } \\
\hline White & $85.9 \%$ & $86.3 \%$ & $86.1 \%$ & $86.1 \%$ \\
\hline Black & $6.2 \%$ & $5.6 \%$ & $5.9 \%$ & $5.8 \%$ \\
\hline Hispanic & $4.1 \%$ & $3.9 \%$ & $3.9 \%$ & $4.1 \%$ \\
\hline Asian or Pacific Islander & $1.5 \%$ & $1.4 \%$ & $1.5 \%$ & $1.4 \%$ \\
\hline Native American & $0.4 \%$ & $0.6 \%$ & $0.4 \%$ & $0.5 \%$ \\
\hline Other & $1.9 \%$ & $2.3 \%$ & $2.2 \%$ & $2.1 \%$ \\
\hline \multicolumn{5}{|l|}{ Hospital Region } \\
\hline Northeast & $13.7 \%$ & $13.7 \%$ & $14.8 \%$ & $12.7 \%$ \\
\hline Midwest & $27.5 \%$ & $27.7 \%$ & $28.3 \%$ & $26.8 \%$ \\
\hline South & $37.7 \%$ & $38.3 \%$ & $35.4 \%$ & $40.4 \%$ \\
\hline West & $21.1 \%$ & $20.3 \%$ & $21.5 \%$ & $20.1 \%$ \\
\hline Teaching Hospital & $44.2 \%$ & $40.6 \%$ & $45.0 \%$ & $40.4 \%$ \\
\hline Elective Admission & $90.9 \%$ & $91.6 \%$ & $92.2 \%$ & $90.1 \%$ \\
\hline \multicolumn{5}{|c|}{ Median household income quartile for patient zipcode } \\
\hline$\$ 1-\$ 38,999$ & $20.2 \%$ & $19.3 \%$ & $17.9 \%$ & $21.7 \%$ \\
\hline$\$ 39,000-\$ 47,999$ & $26.4 \%$ & $26.5 \%$ & $25.5 \%$ & $27.3 \%$ \\
\hline$\$ 48,000-\$ 61,999$ & $26.4 \%$ & $26.1 \%$ & $26.6 \%$ & $25.9 \%$ \\
\hline$>\$ 63,000$ & $27.1 \%$ & $28.1 \%$ & $30.0 \%$ & $25.1 \%$ \\
\hline \multicolumn{5}{|l|}{ Hospital Region } \\
\hline Rural & $9.3 \%$ & $6.3 \%$ & $6.1 \%$ & $9.8 \%$ \\
\hline Urban & $90.7 \%$ & $93.7 \%$ & $93.9 \%$ & $90.2 \%$ \\
\hline
\end{tabular}

In Models 2 and 3, we restricted the control group to patients aged 65-69 years with a non-Medicare or private insurance payer, respectively, in order to understand whether a difference in coding incentives was driving our results. Reimbursement for the care of Medicare patients aged 65-69 (treatment group) would be affected by the payment incentive, while reimbursement for non-Medicare/privately-insured patients aged 65-69 (control group) would not be affected by the payment incentive. Thus, if coding incentives rather than true incidence were driving results, we should see a significant difference in the administrative-data recorded incidence of
PE or DVT amongst the groups compared. In each model, we found no significant difference in the change in incidence of hospital-acquired PE or DVT amongst Medicare and nonMedicare groups ( $p=0.534$ and 0.290 , respectively) (Tables 4 and 5).

\section{DISCUSSION}

CMS hospital payment reform had the desired effect of reducing hospital-acquired pulmonary embolism and deep vein

Table 3. Predictors of Hospital-Acquired Pulmonary Embolism or Deep Vein Thrombosis, Model 1 (Control Group=Patients 60-64 Years with a Non-Medicare Primary Payer)

\begin{tabular}{|c|c|c|c|c|}
\hline Predictor & $\begin{array}{l}\text { Adjusted percentage } \\
\text { point change }\end{array}$ & $\begin{array}{l}95 \% \text { Confidence Interval, } \\
\text { Lower Bound }\end{array}$ & $\begin{array}{l}95 \% \text { Confidence Interval, } \\
\text { Upper Bound }\end{array}$ & $p$ value \\
\hline \multicolumn{5}{|l|}{ Race (reference=White) } \\
\hline Black & $-0.11 \%$ & $-0.37 \%$ & $0.15 \%$ & 0.394 \\
\hline Hispanic & $0.01 \%$ & $-0.32 \%$ & $0.34 \%$ & 0.947 \\
\hline Asian or Pacific Islander & $0.30 \%$ & $-0.29 \%$ & $0.88 \%$ & 0.323 \\
\hline Native American & $-0.84 \%$ & $-1.54 \%$ & $-0.15 \%$ & 0.017 \\
\hline Other & $0.21 \%$ & $-0.26 \%$ & $0.68 \%$ & 0.374 \\
\hline Female & $0.01 \%$ & $-0.02 \%$ & $0.20 \%$ & 0.113 \\
\hline \multicolumn{5}{|c|}{ Hospital Region (reference=Northeast) } \\
\hline Midwest & $-0.12 \%$ & $-0.44 \%$ & $0.19 \%$ & 0.447 \\
\hline South & $-0.02 \%$ & $-0.46 \%$ & $0.12 \%$ & 0.258 \\
\hline West & $0.00 \%$ & $-0.33 \%$ & $0.31 \%$ & 0.945 \\
\hline Teaching Hospital & $0.32 \%$ & $0.14 \%$ & $0.50 \%$ & 0.001 \\
\hline Elective Procedure & $0.25 \%$ & $-0.10 \%$ & $0.59 \%$ & 0.162 \\
\hline \multicolumn{5}{|c|}{ Median household income quartile for patient zipcode (reference $=\$ 1-\$ 38,999$ ) } \\
\hline$\$ 39,000-\$ 47,999$ & $0.11 \%$ & $-0.52 \%$ & $0.27 \%$ & 0.184 \\
\hline$\$ 48,000-\$ 61,999$ & $0.11 \%$ & $-0.09 \%$ & $0.30 \%$ & 0.285 \\
\hline$>\$ 63,000$ & $0.13 \%$ & $-0.08 \%$ & $0.33 \%$ & 0.236 \\
\hline Urban Hospital & $0.11 \%$ & $-0.08 \%$ & $0.30 \%$ & 0.266 \\
\hline Length of Stay & $0.50 \%$ & $0.34 \%$ & $0.66 \%$ & $<0.0001$ \\
\hline Post-intervention & $0.32 \%$ & $0.14 \%$ & $0.50 \%$ & $<0.0001$ \\
\hline Treatment Group & $0.22 \%$ & $0.72 \%$ & $0.37 \%$ & 0.004 \\
\hline Treatment Effect & $-0.28 \%$ & $-0.50 \%$ & $-0.05 \%$ & 0.015 \\
\hline
\end{tabular}




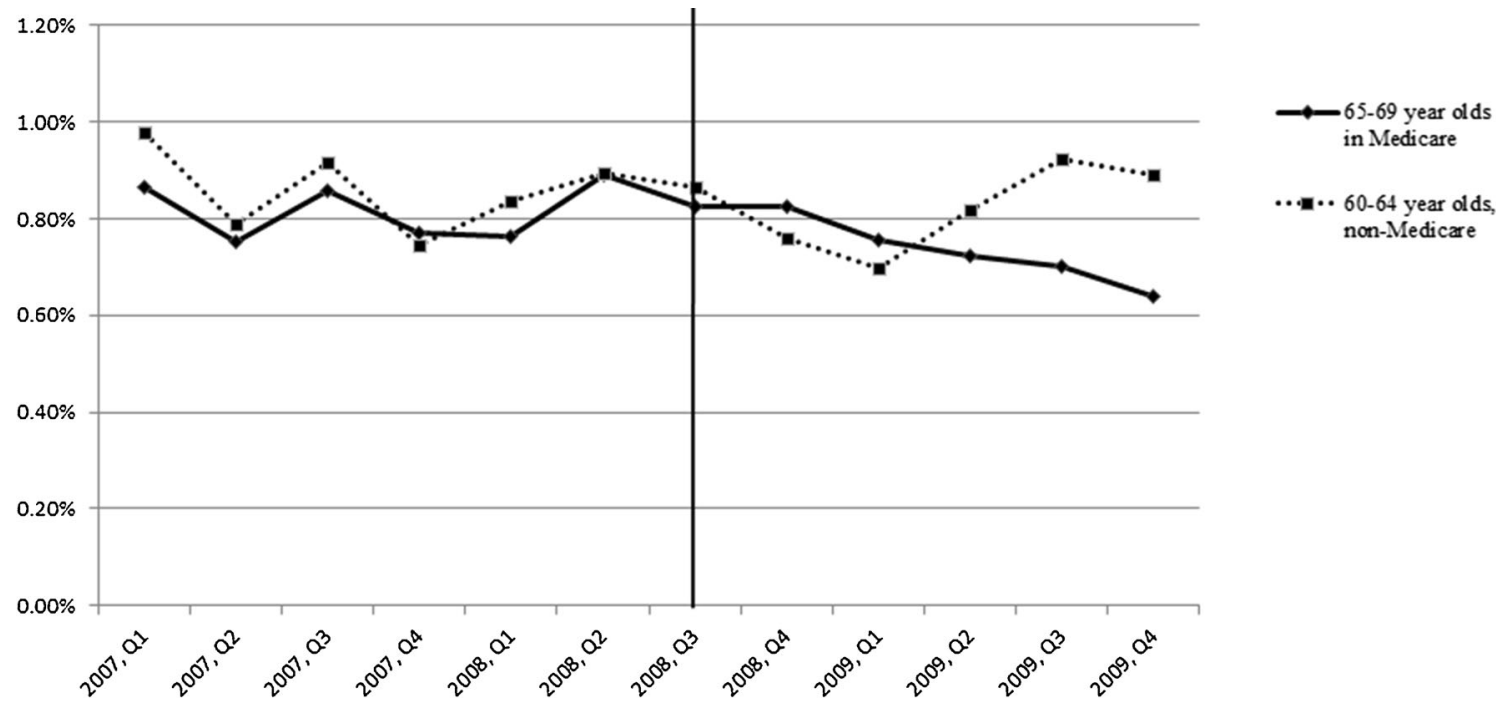

Figure 1. Trend, by quarter and year, of adjusted incidence of pulmonary embolism or deep vein thrombosis, Medicare 65-69 and NonMedicare 60-64.

thrombosis amongst patients with hip or knee replacement surgeries. After controlling for other variables, the policy change was independently associated with a 0.28 percentage point reduction, or a $35 \%$ reduction in the incidence of hospital-acquired PE or DVT amongst Medicare patients aged 65-69 years. We did not find that there was a significant effect associated with payment reform when limiting the control group to patients aged 65-69 with a non-Medicare primary payer. These results suggest that there are some spillover effects of this payment reform into the non-Medicare population, but that they occur according to age, rather than insurance status. Results indicating that payment reform was associated with a significant reduction in PE and DVT over time in the
Medicare population aged 65-69 compared with the nonMedicare population aged 60-64 suggest that providers may be focusing on providing prophylaxis to older patients more than younger patients. The fact that incidence of PE or DVT did not diverge between patients of different insurance status (Medicare versus non-Medicare as the primary payer) also indicates that providers are treating patients 65 years or older similarly, regardless of primary payer. Thus, taken together, our three difference-in-difference models indicate that different coding incentives across the Medicare and non-Medicare populations cannot explain the reduction in PE or DVT in the Medicare population, suggesting that payment reform is associated with a true reduction in incidence of PE or DVT

Table 4. Predictors of Hospital-Acquired Pulmonary Embolism or Deep Vein Thrombosis, Model 2 (Control Group=Patients 65-69 Years with a Non-Medicare Primary Payer)

\begin{tabular}{|c|c|c|c|c|}
\hline$\overline{\text { Predictor }}$ & $\begin{array}{l}\text { Adjusted percentage point } \\
\text { change }\end{array}$ & $\begin{array}{l}95 \% \text { Confidence Interval, Lower } \\
\text { Bound }\end{array}$ & $\begin{array}{l}95 \% \text { Confidence Interval, Upper } \\
\text { Bound }\end{array}$ & $p$ value \\
\hline \multicolumn{5}{|l|}{ Race (reference $=$ White) } \\
\hline Black & $-0.281 \%$ & $-0.558 \%$ & $-0.004 \%$ & 0.047 \\
\hline Hispanic & $-0.075 \%$ & $-0.481 \%$ & $0.331 \%$ & 0.718 \\
\hline Asian or Pacific & $0.435 \%$ & $-0.308 \%$ & $1.178 \%$ & 0.252 \\
\hline \multicolumn{5}{|l|}{ Islander } \\
\hline Native American & $-0.807 \%$ & $-1.102 \%$ & $-0.512 \%$ & $<0.0001$ \\
\hline Other & $0.552 \%$ & $-0.078 \%$ & $1.182 \%$ & 0.086 \\
\hline Female & $0.844 \%$ & $-0.042 \%$ & $0.210 \%$ & 0.189 \\
\hline \multicolumn{5}{|c|}{ Hospital Region (reference $=$ Northeast) } \\
\hline Midwest & $-0.202 \%$ & $-0.581 \%$ & $0.176 \%$ & 0.295 \\
\hline South & $-0.040 \%$ & $-0.402 \%$ & $0.322 \%$ & 0.829 \\
\hline West & $0.056 \%$ & $-0.342 \%$ & $0.455 \%$ & 0.782 \\
\hline Teaching Hospital & $0.351 \%$ & $0.133 \%$ & $0.568 \%$ & 0.002 \\
\hline Elective Procedure & $0.549 \%$ & $0.142 \%$ & $0.955 \%$ & 0.008 \\
\hline \multicolumn{5}{|c|}{ Median household income quartile for patient zipcode (reference $=\$ 1-\$ 38,999)$} \\
\hline$\$ 39,000-\$ 47,999$ & $0.003 \%$ & $-0.195 \%$ & $0.202 \%$ & 0.974 \\
\hline$\$ 48,000-\$ 61,999$ & $0.047 \%$ & $-0.180 \%$ & $0.274 \%$ & 0.683 \\
\hline$>\$ 63,000$ & $0.164 \%$ & $-0.073 \%$ & $0.401 \%$ & 0.174 \\
\hline Urban Hospital & $-0.078 \%$ & $-0.324 \%$ & $0.167 \%$ & 0.532 \\
\hline Length of Stay & $0.554 \%$ & $0.357 \%$ & $0.752 \%$ & $<0.0001$ \\
\hline Post-intervention & $0.182 \%$ & $-0.118 \%$ & $0.482 \%$ & 0.234 \\
\hline Treatment Group & $0.140 \%$ & $-0.077 \%$ & $0.357 \%$ & 0.207 \\
\hline Treatment Effect & $-0.103 \%$ & $-0.428 \%$ & $0.222 \%$ & 0.534 \\
\hline
\end{tabular}


Table 5. Predictors of Hospital-Acquired Pulmonary Embolism or Deep Vein Thrombosis, Model 2 (Control Group=Patients 65-69 Years with Private Insurance as the Primary Payer)

\begin{tabular}{|c|c|c|c|c|}
\hline Predictor & $\begin{array}{l}\text { Adjusted percentage point } \\
\text { change }\end{array}$ & $\begin{array}{l}95 \% \text { Confidence Interval, Lower } \\
\text { Bound }\end{array}$ & $\begin{array}{l}95 \% \text { Confidence Interval, Upper } \\
\text { Bound }\end{array}$ & $p$-value \\
\hline \multicolumn{5}{|c|}{ Race (reference=White) } \\
\hline Black & -0.003 & -0.006 & 0.000 & 0.024 \\
\hline Hispanic & 0.000 & -0.004 & 0.004 & 0.952 \\
\hline Asian or Pacific & 0.006 & -0.003 & 0.014 & 0.180 \\
\hline \multicolumn{5}{|l|}{ Islander } \\
\hline Native American & -0.008 & -0.011 & -0.005 & $<0.0001$ \\
\hline Other & 0.006 & -0.001 & 0.125 & 0.076 \\
\hline Female & 0.001 & 0.000 & 0.002 & \\
\hline \multicolumn{5}{|c|}{ Hospital Region (reference $=$ Northeast $)$} \\
\hline Midwest & -0.002 & -0.006 & 0.002 & 0.281 \\
\hline South & -0.004 & -0.004 & 0.003 & 0.839 \\
\hline West & 0.001 & -0.003 & 0.005 & 0.711 \\
\hline Teaching Hospital & 0.004 & 0.001 & 0.006 & 0.001 \\
\hline Elective Procedure & 0.005 & 0.001 & 0.009 & 0.024 \\
\hline \multicolumn{5}{|c|}{ Median household income quartile for patient zipcode (reference $=\$ 1-\$ 38,999$ ) } \\
\hline$\$ 39,000-\$ 47,999$ & 0.000 & -0.002 & 0.002 & 0.971 \\
\hline$\$ 48,000-\$ 61,999$ & 0.000 & -0.002 & 0.003 & 0.846 \\
\hline$>\$ 63,000$ & 0.002 & -0.001 & 0.004 & 0.183 \\
\hline Urban Hospital & -0.001 & -0.003 & 0.002 & 0.481 \\
\hline Length of Stay & 0.006 & 0.004 & 0.008 & $<0.0001$ \\
\hline Post-intervention & 0.003 & -0.001 & 0.006 & 0.115 \\
\hline Treatment Group & 0.001 & -0.001 & 0.004 & 0.237 \\
\hline Treatment Effect & -0.002 & -0.005 & 0.002 & 0.290 \\
\hline
\end{tabular}

amongst patients aged 65 and older, and that there are some positive spillover effects from Medicare policies to other patients aged 65 and older without Medicare as a primary payer.

We included length of stay as a covariate in each model to evaluate whether Medicare patients were being discharged earlier over time and therefore leaving the hospital before having the opportunity to develop PE or DVT. Including or excluding length of stay did not change the direction or significance of the effect of the payment intervention. Furthermore, length of stay was always longer in the Medicare population than in the non-Medicare population (Table 6), indicating that earlier discharge for Medicare patients was not a factor in the reduction in incidence of PE or DVT from 2007 to 2009.

The incidence of PE or DVT begins to diverge amongst the Medicare and non-Medicare population at the beginning of 2009, approximately one quarter after the implementation of the policy. It is possible that hospitals reviewed their revenue in the first quarter after this policy change and modified their practices to avoid further decreases in CMS-based reimbursement.

Our results indicate that the incidence of PE or DVT increased in the comparator group, while it decreased in the (treatment) group of non-Medicare patients aged 60 to 64 years. There are two possible explanations for this. It is possible that the CMS policy may have decreased the attention paid by hospitals to these younger, non-Medicare patients, as payments for those patients did not hinge (after the reform) on PE or DVT outcomes. If this is indeed the case, this points to the need for private payers to adopt a similar policy to avoid any loss that comes from welfare shifting. However, there also exists the possibility that in the absence of the intervention, the incidence of PE or DVT in the Medicare population would have also risen, and that this payment policy staved off potential harm that Medicare patients would have faced in the absence of this intervention.

Our model indicates a 0.28 percentage point reduction, or a $35 \%$ reduction, in the incidence of hospital-acquired PE or DVT associated with payment reform. While this percentage point reduction may appear small, given the sheer volume of hip and knee replacement surgeries in the United States, it represents a major cost savings for the Medicare program. In 2009, CMS paid for 562,863 hospitalizations for MS-DRGs 461, 462, 469 and 470, which represent DRGs for hip and knee replacement surgeries. Using Medicare payment and discharge data from fiscal year (FY) 2009, we calculated the cost savings associated with a $35 \%$ reduction in PE or DVT in these DRGs. ${ }^{28}$ These DRGs also include ankle replacements, and ankle, foot, and lower limb reattachments ${ }^{29}$; we generously estimated $10 \%$ of discharges were for such purposes. Using FY 2009 Medicare reimbursement rates for these procedures ${ }^{28}$ we estimated a $35 \%$ reduction in payment for hospital-acquired conditions would save Medicare approximately $\$ 89$ million in one year. It is improbable that the cost of administering this portion of the hospital-acquired condition payment reform program approaches this dollar figure; therefore, CMS is most likely experiencing substantial cost savings under this payment reform.

Table 6. Mean Length of Stay

\begin{tabular}{lll}
\hline \hline Year & $\begin{array}{l}\text { 60-64 year-olds, } \\
\text { non-Medicare (SD) }\end{array}$ & $\begin{array}{l}\text { 65-69 year-olds, } \\
\text { Medicare (SD) }\end{array}$ \\
\hline 2007 & $3.55(2.13)$ & $3.69(2.63)$ \\
2008 & $3.38(2.30)$ & $3.53(1.91)$ \\
2009 & $3.32(1.84)$ & $3.43(1.96)$ \\
\hline
\end{tabular}


To our knowledge, this is the first study to analyze the effect of CMS payment modifications on the incidence of pulmonary embolism or deep vein thrombosis. One study evaluated the effect of CMS payment reform for a different hospitalacquired condition. Using data from 398 hospitals reported to a national public health surveillance system, Lee et al. found no impact of CMS payment policies on the incidence of catheter-associated bloodstream infections or catheterassociated urinary tract infections. ${ }^{30}$ However, authors did not have information on insurance status of patients, so it is possible that the incidence of catheter-associated infections differed among Medicare and non-Medicare patients. The difference in findings regarding the effect of CMS payment reform between our study and that of Lee et al. is likely also explained by the disparate conditions studied. Due to the ability to pharmacologically provide prophylaxis to patients, avoiding PE or DVT may require fewer hospital resources and/or changes in care practice compared with those required to lower the incidence of catheter-associated infections.

Our modeling approach employed hierarchical linear regression, using hospital as a random effect to account for clustering of observations within hospital. The choice of a hierarchical regression model rather than a samplingweighted model was driven by both theoretical considerations $^{31}$ as well as practical concerns. Not all hospitals in our data set had a discharge for a hip or knee replacement. Therefore, using existing NIS survey weights would result in erroneously smaller standard errors, ${ }^{26}$ thereby increasing the risk of Type I error. Nevertheless, we evaluated the effect of model specification on results by employing both a linear probability model using sampling weights and a logistic regression model using sampling weights; changes to model specification did not impact study conclusions. In each case, the predicted marginal probabilities were similar, and the $p$ values for the interaction term were all significant.

This was a retrospective analysis of administrative data using a quasi-experimental technique. There are limitations associated with this approach. The analysis relied exclusively on ICD-9-CM billing codes to determine frequency of procedures and complication rates. There are concerns that billing data may not accurately reflect care. ${ }^{32,33}$ However, as this analysis uses a relative approach, inaccuracy of ICD-9-CM codes would only be of concern if there are systematic differences in coding inaccuracies across Medicare versus nonMedicare patients or pre-intervention versus postintervention coding practices. CMS recently conducted a chart review of coding for PE and DVT for Medicare beneficiaries in FY 2009 and 2010 and found no discrepancies in the chartrecorded incidence of PE or DVT and the administrative-data based reporting of PE or DVT; there was a $100 \%$ concordance between the two. ${ }^{34}$ Therefore, PE or DVT coding inaccuracy is unlikely to exist in the Medicare population. Additionally, given that there is no financial incentive to under-record PE or DVT in the non-Medicare population, we believe it highly unlikely that coding inaccuracies are driving our conclusions. There was no flag for present on admission within the data set, so this analysis was not able to exclude patients whose pulmonary embolism or deep vein thrombosis was present prior to surgery. However, this is not a substantial limitation, as it is unlikely that patients with such a serious existing condition would experience this type of operation. We found that teaching hospitals had significantly higher PE or DVT; this could be due to either a sicker population or due to processes of care. It is not possible to tease out the reason for this finding from the available data.

While the NIS is a nationally representative sample of community-hospital discharges in the United States, not all states are included in all years of the NIS. Louisiana, Pennsylvania, Montana and New Mexico did not contribute data for 2007, 2008 and 2009, and were therefore dropped from the analysis. Maine was also dropped due to a lack of data regarding insurance status. Therefore, results should be interpreted as being nationally representative while excluding these five states.

\section{CONCLUSION}

As the U.S. healthcare system increasingly moves from feefor-service to fee-for-value reimbursement, or reimbursement based on achieving higher quality care at lower total costs, it becomes important to evaluate whether fee-for-value reimbursement has a desired effect. Using a statistical method to control for larger secular trends that may have affected the practice of treating orthopedic patients in the United States, this analysis found that CMS's refusal to pay for hospitalacquired pulmonary embolism or deep vein thrombosis after hip or knee replacement was associated with a $35 \%$ reduction in the incidence proportion of these conditions in Medicare patients. Our findings indicate that CMS's payment reform for hospital-acquired conditions had an effect of reducing the incidence of PE and DVT on patients aged 65 years or older, regardless of their primary insurance payer.

Acknowledgements: Dr. Gidwani had full access to all of the data in the study and takes responsibility for the integrity of the data and the accuracy of the data analysis.

Conflicts of Interest: The authors declare that they do not have a conflict of interest.

Corresponding Author: Risha Gidwani, Dr.P.H.; Centers for Health Policy, Primary Care and Outcomes ResearchStanford University, Stanford, CA, USA (e-mail: risha.gidwani@va.gov).

\section{REFERENCES}

1. Centers for Medicare \& Medicaid Services. Hospital-Acquired Conditions (Present on Admission Indicator). 2012; http://www.cms.gov/Medicare/ 
Medicare-Fee-for-Service-Payment/HospitalAcqCond / index.html?redirect=/hospitalacqcond. Accessed October 17, 2014.

2. West N ET, Kirk A. Update on State Government Tracking of Health CareAcquired Conditions and a Four-State In-Depth Review. June 2012; https://www.cms.gov/Medicare/Medicare-Fee-for-Service-Payment/ HospitalAcqCond/Downloads/Phase-3-State-Tracking-Report.pdf. Accessed October 17, 2014.

3. Stone PW, Glied SA, McNair PD, et al. CMS changes in reimbursement for HAIs: setting a research agenda. Med Care. 2010;48(5):433.

4. Centers for Medicare \& Medicaid Services. HCUPnet: A tool for identifying, tracking, and analyzing national hospital statistics. 2013; http:// hcupnet.ahrq.gov/HCUPnet.jsp. Accessed October 17, 2014.

5. American Academy of Orthopedic Surgeons (AAOS). American Academy of Orthopedic Surgeons clinical practice guideline on preventing venous thromboembolic disease in patients undergoing elective hip and knee arthroplasty. Rosemont (IL): American Academy of Orthopedic Surgeons (AAOS); 2011.

6. Office of the Surgeon General (US). National Heart, Lung, and Blood Institute (US). The Surgeon General's Call to Action to Prevent Deep Vein Thrombosis and Pulmonary Embolism. 2008; http:// www.ncbi.nlm.nih.gov/books/NBK44181/. Accessed October 17, 2014.

7. Centers for Medicare \& Medicaid Services. Evidence-based Guidelines for Selected and Previously Considered Hospital-Acquired Conditions. 2013; http://www.cms.gov/Medicare/Medicare-Fee-for-Service-Payment/ HospitalAcqCond/Downloads/Evidence-Based-Guidelines.pdf. Accessed October 17, 2014.

8. Maynard GA, Morris TA, Jenkins IH, et al. Optimizing prevention of hospital-acquired venous thromboembolism (VTE): prospective validation of a VTE risk assessment model. J Hosp Med. 2010;5(1):10-18.

9. Glickman Sw, Ou F-S, DeLong ER, et al. Pay for performance, quality of care, and outcomes in acute myocardial infarction. JAMA. 2007;297(21):2373-2380.

10. Jha AK, Joynt KE, Orav EJ, Epstein AM. The long-term effect of premier pay for performance on patient outcomes. New Eng J Med. 2012;366(17):1606-1615.

11. Lindenauer PK, Remus D, Roman S, et al. Public reporting and pay for performance in hospital quality improvement. New Eng $\mathrm{J}$ Med. 2007;356(5):486-496.

12. Nahra TA, Reiter KL, Hirth RA, Shermer JE, Wheeler JR. Costeffectiveness of hospital pay-for-performance incentives. Medical Care Research and Review. 2006;63(1 suppl):49S-72S.

13. Ryan AM. Effects of the Premier Hospital Quality Incentive Demonstration on Medicare patient mortality and cost. Health Serv Res. 2009;44(3):821842.

14. Werner RM, Kolstad JT, Stuart EA, Polsky D. The effect of pay-forperformance in hospitals: lessons for quality improvement. Health Affairs. 2011;30(4):690-698.

15. Straube B, Blum JD. The policy on paying for treating hospital-acquired conditions: CMS officials respond. Health Affairs. 2009;28(5):1494-1497.

16. Centers for Medicare \& Medicaid Services. Hospital-Acquired Conditions (HAC) in Acute Inpatient Prospective Payment System (IPPS) Hospitals. 2012; http://www.cms.gov/Medicare/Medicare-Fee-for-Service-Payment/ HospitalAcqCond/downloads/hacfactsheet.pdf. Accessed October 17, 2014.

17. Angrist JD. Estimation of limited dependent variable models with dummy endogenous regressors. Journal of Business \& Economic Statistics. 2001;19 (1)

18. Card D, Krueger AB. Minimum Wages and Employment: A Case Study of the Fast-Food Industry in New Jersey and Pennsylvania. American Economic Review. 1994;84:772-793.

19. Gruber J, Poterba J. Tax incentives and the decision to purchase health insurance: Evidence from the self-employed. Q J Econ. 1994;109(3):701733.

20. Meyer BD, Viscusi WK, Durbin DL. Workers' compensation and injury duration: evidence from a natural experiment. American Economic Review. 1995;85:322-340.

21. Block LD, Jarlenski MP, Wu AW, Bennett WL. Mammography Use Among Women Ages 40-49 After the 2009 US Preventive Services Task Force Recommendation. J Gen Intern Med. 2013:1-7

22. Farrar S, Yi D, Sutton M, Chalkley M, Sussex J, Scott A. Has payment by results affected the way that English hospitals provide care? Differencein-differences analysis. BMJ. 2009;339.

23. Stuart B, Davidoff A, Erten M, et al. How Medicare Part D Benefit Phases Affect Adherence with Evidence-Based Medications Following Acute Myocardial Infarction. Health Serv Res. Jun 62013 Jun 6 [Epub ahead of print].
24. Bertrand M, Duflo E, Mullainathan s. How much should we trust differences-in-differences estimates? Q J Econ. 2004;119(1):249-275.

25. Rabe-Hesketh S, Skrondal A. Multilevel and longitudinal modelling using Stata. College Station, T.X.: STATA press; 2008.

26. Houchens R, Elixhauser A. Final report on calculating nationwide inpatient sample (NIS) variances, 2001. HCUP Methods Series Report\# 2003-2. Online. June 2005 (revised June 6, 2005). US Agency for Healthcare Research and Quality;2005.

27. Wooldridge JM. Binary response models. Econometric analysis of cross section and panel data. Cambridge, M.A.: The MIT Press; 2002.

28. Centers for Medicare \& Medicaid Services. 100\% MEDPAR Inpatient Hospital National Data for Fiscal Year 2009. 2009; http://www.cms.gov/ Research-Statistics-Data-and-Systems/Statistics-Trends-and-Reports / MedicareFeeforSvcPartsAB/Downloads/DRG09.pdf. Accessed July 25, 2014.

29. Ingenix Inc. DRG Expert 2009: A comprehensive guidebook to the DRG classification system. 25th ed: Optuminsight Incorporated; 2008.

30. Lee GM, Kleinman $\mathbf{K}$, Soumerai SB, et al. Effect of nonpayment for preventable infections in US hospitals. New Eng $J$ Med. 2012;367(15): 1428-1437.

31. Houchens R, Chu B, Steiner C. Hierarchical modeling using HCUP data. HCUP Methods Series. 2007;2007-2001.

32. Classen DC, Resar R, Griffin F, et al. 'Global trigger tool' shows that adverse events in hospitals may be ten times greater than previously measured. Health Affairs. 2011;30(4):581-589.

33. Meddings JA, Reichert H, Rogers MA, Saint S, Stephansky J, McMahon LF. Effect of Nonpayment for Hospital-Acquired, CatheterAssociated Urinary Tract Infection: A Statewide Analysis. Ann Intern Med. 2012;157(5):305-312.

34. Centers for Medicare \& Medicaid Services. Accuracy of Coding in the Hospital-Acquired Conditions-Present on Admission Program. 2012; http://www.cms.gov/Medicare/Medicare-Fee-for-Service-Payment/ HospitalAcqCond/Downloads /Accuracy-of-coding-Final-Report.pdf. Accessed October 17, 2014.

35. Wooldridge JM. Additional single-equation topics. Econometric analysis of cross section and panel data. Cambridge, M.A.: The MIT Press; 2002.29.

36. Buckley J, Shang Y. Estimating policy and program effects with observational data: the "differences-in-differences" estimator. Practical Assess, Res \& Eval. 2003;8:24.

37. Angrist JD. Estimation of limited dependent variable models with dummy endogenous regressors. J Business \& Econ Stat. 2001;19 (1).

\section{APPENDIX: FURTHER DETAILS ABOUT MODELING APPROACH}

The difference-in-differences approach uses a linear probability model with the following form ${ }^{35}$ :

$\mathrm{Y}=\alpha+\beta_{1} \mathrm{X}_{1}+\beta_{2} \mathrm{X}_{2}+\beta_{3} \mathrm{X}_{1} * \mathrm{X}_{2}+\varepsilon$

Where $\mathrm{Y}$ is the outcome of interest, $\alpha$ is the common constant for all observations, $\mathrm{X}_{1}$ is a dummy variable for the first difference, and $\mathrm{X}_{2}$ is a dummy variable for the second difference, $\varepsilon$ is the error term, and the $\beta$ s are the coefficients for each variable. The coefficient of interest is $\beta_{3}$, which estimates the outcome for the treatment group post-intervention (when both $\mathrm{X}_{1}$ and $\mathrm{X}_{2}$ equal 1), also known as the effect of the treatment on the treated. The coefficient $\beta_{3}$ is derived from Eq. $2^{35}$ :

$\beta_{3}=\left(\overline{\mathrm{Y}} \mathrm{B}_{2}-\overline{\mathrm{Y}} \mathrm{B}_{1}\right)-\left(\overline{\mathrm{Y}} \mathrm{A}_{2}-\overline{\mathrm{Y}} \mathrm{A}_{1}\right)$

Where $\bar{Y} \quad B_{1}$ is the sample average for the treatment group pre-intervention, $\overline{\mathrm{Y}} \mathrm{B}_{2}$ is the sample average for the treatment group post-intervention, $\bar{Y} \quad A_{1}$ is the sample average for the 
control group pre-intervention, and $\overline{\mathrm{Y}} \quad \mathrm{A}_{2}$ is the sample average for the treatment group post-intervention.

Linear probability models are generally used in differencein-difference modeling, even when the outcome of interest is binary. ${ }^{35,36}$ One of the concerns with linear probability models for binary outcomes is that they may predict outside of the probability range of $0-1$. Angrist argues that linear models can be used for binary outcomes when one is interested in computing average, or marginal, effects, rather than conditional probabilities. $^{37} \mathrm{He}$ demonstrates remarkably similar means and standard errors from OLS and from probit models of a binary outcome. Additionally, when predictors include variables for mutually exclusive and exhaustive categories, as they do here given the inclusion criteria or hip and knee surgeries and the exclusion criterion of all people who are not 60 69 years old, the fitted values from the linear probability model are the average outcome within each cell and do not exceed the interval $0-1 .{ }^{35}$ 